\title{
Eyelid Carcinoma by AJCC v7 Stage
}

National Cancer Institute

\section{Source}

National Cancer Institute. Eyelid Carcinoma by A/CC v7 Stage. NCI Thesaurus. Code C140511.

A term that refers to the staging of eyelid carcinoma according to the American Joint Committee on Cancer, 7 th edition. 